\title{
CAUSES AND PATTERNS OF TOOTH EXTRACTION AMONG THE PATIENTS ATTENDING A DENTAL HOSPITAL IN PESHAWAR, PAKISTAN
}

\author{
Muhammad Ilyas ${ }^{1}$, Jawad Ahmad Kundi', Sara Khan ${ }^{1}$, Ambreen ${ }^{1}$, Sumaira Amin ${ }^{1}$, Tehmina Shah \\ Nawaz Khan ${ }^{1}$
}

\author{
1. Sardar Begum Dental College
}

\begin{abstract}
OBJECTIVE

The aim of this study was to determine the primary reasons for tooth extraction and the type of tooth involved in extraction.

\section{METHODOLOGY}

A cross-sectional study was conducted after the approval of the ethical committee of the hospital at the Department of Oral and Maxillofacial Surgery, Sardar Begum Dental Hospital from July 2015 to December 2015. A total of $n=4230$ permanent tooth extractions were included with female $n=2532$ and male $n=1698$. The primary reasons for tooth extraction specified were caries, periodontal diseases, prosthetic and orthodontic purposes, impaction and trauma. The data was analyzed using SPSS-22. Descriptive statistics was applied for causes and frequency of tooth extraction. Chi-square tests were performed using $p \leq 0.05$ significance level to determine if any significant difference existed among the genders.
\end{abstract}

\section{RESULTS}

The mean age presentation was 39.6 \pm 15.9 years and the age range 13-70 years. The female patient predominate $n=2532$ (59.85\%) the male patients $n=1698$ (40.12\%). Caries was the dominant cause of extraction in both subjects $n=2652(62.70 \%)$, followed by periodontal disease $n=930(22.00 \%)$, prosthetic purpose $n=366$ (8.70\%), orthodontic purpose $n=156$ (3.70\%) while cause of extraction due to trauma $n=30$ $(0.70 \%)$ was the least one in both subjects. In female the dominant arch is mandibular arch $n=1404(55.45 \%)$ than maxillary arch $n=1128$ (44.55\%) while in male maxillary arch $n=906(53.36 \%)$ predominate the mandibular arch $n=792(46.64 \%)$. First permanent molars $n=936(11.07 \%)$ were the most common tooth type involved in tooth extraction in both genders [upper: $n=408$ (9.64\%), lower: $n=528(12.50 \%)$ ]. Upper central incisor $n=120(2.84 \%)$ is the least common tooth involved in tooth extraction. The chi-square test illustrates that there is no significant difference exist among both subjects (chi-square $=0.9797, p=0.323$ ).

\section{CONCLUSION}

Caries is the dominant cause of extraction and the most frequent teeth involved in extraction is lower first molar.

\section{KEYWORDS}

Tooth extraction, Caries, Periodontal disease, First molar.

\section{INTRODUCTION}

Tooth extraction may lead to unwanted dental pain and fear therefore, it is important to

Correspondence:

Dr. Muhammad llyas

Sardar Begum Dental College Contact: 0302-8809637

Email: ilyas_khan526@yahoo.com

https://doi.org/10.37762/jgmds.3-01.42 minimize the liability of tooth extraction ${ }^{1}$. The tooth loss may provokes drifting or tilting of teeth, which may results in caries, periodontal diseases, orthodontics and temporo-mandibular joint problems ${ }^{2}$, psychological stress and development of negative morale ${ }^{3}$. The cost is another concern for correcting these problems leading to increase load on the patients ${ }^{4}$. The causes of extraction vary amongst different countries. Dental caries was the main cause of extraction ${ }^{5-8}$, but a few studies revealed that periodontal disease appears 
to be the main cause of tooth loss ${ }^{9-11}$. While other studies found that carries and periodontal disease were equally responsible for tooth extraction ${ }^{12,13}$. In many studies, caries reported to be the most frequent cause for tooth loss in early age group ${ }^{5,14}$ and that of periodontal disease was the main reason for tooth extraction in older patients ${ }^{5,15,16}$. The aim of this study was to evaluate the primary reasons for tooth extraction and the type of tooth involved in extraction.

\section{METHODOLGY}

A cross-sectional study was conducted after the approval of the ethical committee of the hospital at the Department of Oral and Maxillofacial Surgery, Sardar Begum Dental Hospital from July 2015 to December 2015. A total of $n=4230$ permanent tooth extractions were included with female $n=2532$ and male $n=1698$. All diabetic, hypertensive, immune-compromised and patients undergoing chemotherapy or radiotherapy were excluded. The data was collected from the patients through performas and informed consent taken from each patient. The primary reasons for tooth extraction specified were caries, periodontal diseases, prosthetic and orthodontic purposes, impaction and trauma. Definition of these primary reasons for extraction was modified from study by Klock KS ${ }^{17}$. The data was analyzed using SPSS-22. Descriptive statistics was applied for causes and frequency of tooth extraction. Chi-square tests were performed using $p \leq 0.05$ significance level to determine if any significant difference existed among the genders.

\section{RESULTS}

The mean age presentation was $39.6 \pm 15.9$ years and the age range $13-70$ years. The female patient predominate $n=2532(59.85 \%)$ the male patients $n=1698(40.12 \%)$. Caries was the dominant cause of extraction in both subjects $n=2652(62.70 \%)$, followed by periodontal disease $n=930(22.00 \%)$, prosthetic purpose $n=366(8.70 \%)$, orthodontic purpose $n=156(3.70 \%)$ while cause of extraction due to trauma $n=30(0.70 \%)$ was the least one in both subjects. In female the cause of extraction due to prosthetic $n=258(10.20 \%)$ and orthodontic $n=114(4.50 \%)$ purpose are prominent than male showing that female are more cautious to their esthetic. The causes of extraction is shown in table. 1 and percentage of tooth extraction is given in figure. 1

The most frequent arch involved in tooth extraction varies in both subjects is shown in figure.2. In female the dominant arch is mandibular arch $n=1404(55.45 \%)$ than maxillary arch $n=1128(44.55 \%)$ while in male maxillary arch $n=906(53.36 \%)$ predominate the mandibular arch $n=792(46.64 \%)$. Table.2 demonstrates the number of extractions of specific tooth and percentage in male and female patients. First permanent molars $n=936(11.07 \%)$ were the most common tooth type involved in tooth extraction in both genders [upper: $n=408(9.64 \%)$, lower: $n=528(12.50 \%)$ ]. Upper central incisor $n=120(2.84 \%)$ is the least common tooth involved in tooth extraction. The chisquare test illustrates that there is no significant difference exist among both subjects(chisquare $=0.9797, p=0.323$ ).

Figure \# 1: Percentage of tooth extraction amongst male and female patients

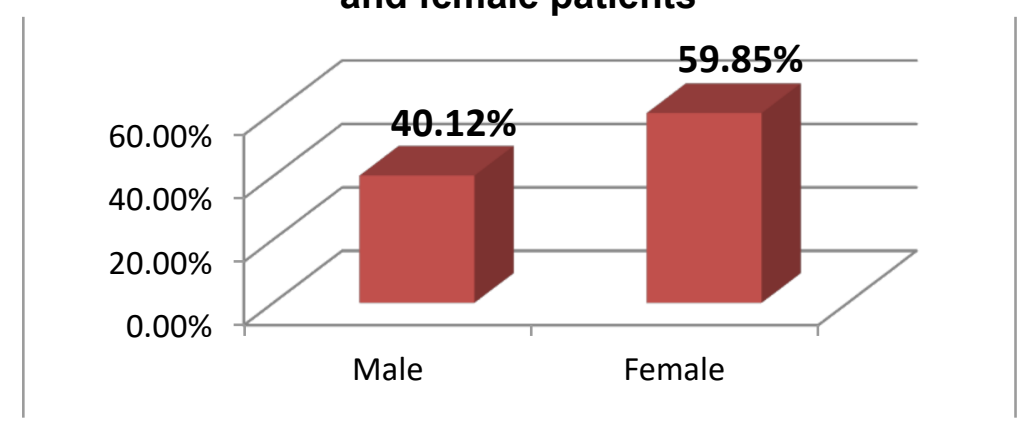


Figure \# 2: Percentage of type of tooth extraction

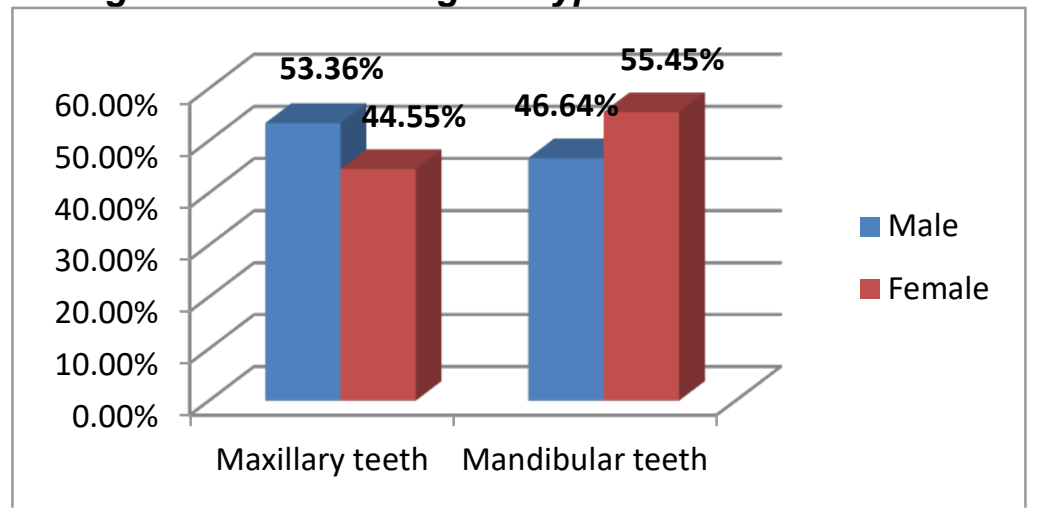

Table 1: Showing causes of extractions in numbers and percentage in male and female patients.

\begin{tabular}{|llll|}
\hline Causes & Male =n (\%) & Female =n (\%) & Total =n (\%) \\
\hline Caries & $1080(63.60 \%)$ & $1572(62.10 \%)$ & $2652(62.70 \%)$ \\
\hline Periodontal diseases & $396(23.32 \%)$ & $534(21.10 \%)$ & $930(22.00 \%)$ \\
\hline Prosthetic purpose & $108(6.36 \%)$ & $258(10.20 \%)$ & $366(8.70 \%)$ \\
\hline Orthodontic purpose & $42(2.50 \%)$ & $114(4.50 \%)$ & $156(3.70 \%)$ \\
\hline Impaction & $54(3.18 \%)$ & $42(1.66 \%)$ & $96(2.27 \%)$ \\
\hline Trauma & $18(1.06 \%)$ & $12(0.47 \%)$ & $30(0.70 \%)$ \\
\hline Total =n (\%) & $\mathbf{1 6 9 8 ( 1 0 0 \% )}$ & $\mathbf{2 5 3 2 ( 1 0 0 \% )}$ & $\mathbf{4 2 3 0 ( 1 0 0 \% )}$ \\
\hline
\end{tabular}

Table 2: Showing number of extractions of specific tooth and percentage in male and female patients

\begin{tabular}{|c|c|c|c|}
\hline Name of the tooth & Male $=n(\%)$ & Female $=n(\%)$ & Total $=n(\%)$ \\
\hline $\begin{array}{r}\text { Central Incisor } \\
\text { Upper } \\
\text { Lower }\end{array}$ & $\begin{array}{l}48(2.83 \%) \\
60(3.53 \%)\end{array}$ & $\begin{array}{l}72(2.84 \%) \\
84(3.32 \%)\end{array}$ & $\begin{array}{l}120(2.84 \%) \\
144(3.40 \%)\end{array}$ \\
\hline $\begin{array}{r}\text { Lateral Incisor } \\
\text { Upper } \\
\text { Lower }\end{array}$ & $\begin{array}{l}72(4.24 \%) \\
66(3.89 \%)\end{array}$ & $\begin{array}{l}96(3.80 \%) \\
90(3.60 \%)\end{array}$ & $\begin{array}{l}168(3.97 \%) \\
156(3.69 \%)\end{array}$ \\
\hline $\begin{aligned} & \text { Canine } \\
& \text { Upper } \\
& \text { Lower }\end{aligned}$ & $\begin{array}{l}72(4.24 \%) \\
54(3.18 \%)\end{array}$ & $\begin{array}{l}114(4.50 \%) \\
72(2.84 \%)\end{array}$ & $\begin{array}{l}186(4.40 \%) \\
126(3.00 \%)\end{array}$ \\
\hline $\begin{array}{r}\text { First Premolar } \\
\text { Upper } \\
\text { Lower }\end{array}$ & $\begin{array}{l}102(6.01 \%) \\
54(3.18 \%)\end{array}$ & $\begin{array}{l}222(8.77 \%) \\
168(6.64 \%)\end{array}$ & $\begin{array}{l}324(7.66 \%) \\
222(5.25 \%)\end{array}$ \\
\hline $\begin{array}{c}\text { Second Premolar } \\
\text { Upper } \\
\text { Lower }\end{array}$ & $\begin{array}{l}150(8.84 \%) \\
84(4.94 \%)\end{array}$ & $\begin{array}{l}138(5.45 \%) \\
168(6.64 \%)\end{array}$ & $\begin{array}{l}288(6.81 \%) \\
252(6.00 \%)\end{array}$ \\
\hline $\begin{array}{r}\text { First Molar } \\
\text { Upper } \\
\text { Lower } \\
\end{array}$ & $\begin{array}{l}186(10.95 \%) \\
204(12.01 \%) \\
\end{array}$ & $\begin{array}{l}222(8.77 \%) \\
324(12.80 \%) \\
\end{array}$ & $\begin{array}{l}408(9.64 \%) \\
528(12.50 \%)\end{array}$ \\
\hline $\begin{array}{r}\text { Second Molar } \\
\text { Upper } \\
\text { Lower }\end{array}$ & $\begin{array}{l}138(8.13 \%) \\
126(7.42 \%)\end{array}$ & $\begin{array}{l}156(6.17 \%) \\
282(11.14 \%)\end{array}$ & $\begin{array}{l}294(6.95 \%) \\
408(9.64 \%)\end{array}$ \\
\hline $\begin{array}{r}\text { Third Molar } \\
\text { Upper } \\
\text { Lower }\end{array}$ & $\begin{array}{l}138(8.13 \%) \\
144(8.48 \%)\end{array}$ & $\begin{array}{l}108(4.27 \%) \\
216(8.53 \%)\end{array}$ & $\begin{array}{l}246(5.81 \%) \\
360(8.50 \%)\end{array}$ \\
\hline Total $=n(\%)$ & $1698(100 \%)$ & $2532(100 \%)$ & $4230(100 \%)$ \\
\hline
\end{tabular}




\section{DISCUSSION}

This study revealed that caries $(62.70 \%)$ turn out to be the predominant cause of tooth extraction amongst patient reported to the hospital. This finding is in consistent with the study done at different parts of the world ${ }^{5-8}$ while some study contradicts our study showing that periodontal diseases is the primary reason for tooth extraction ${ }^{9-11}$. Corbetet al $^{18}$ in his study found that caries $(60 \%)$ was the dominant cause of extraction followed by periodontitis which is in agreement with our study. Naz et $\mathrm{al}^{19}$ found that carries and it's sequelea accounted for $42.2 \%$ extractions and was the dominant cause in her study but lower than in our study. Nasreenet $\mathrm{al}^{20}$ revealed that caries $(68 \%)$ was the cause of dental extraction which support our study. Trauma $(0.70 \%)$ was the least common cause in both male and female patients while periodontal disease $(22 \%)$ was the second most common reason for extraction in our study which is in agreement with study done by Gossadiet $\mathrm{al}^{21}$. This study shows that female patients $(59.85 \%)$ dominate male patients $(40.12 \%)$ in terms of tooth extraction which contradict the western population ${ }^{22}$ and the study done by HaseebM et $a^{23}$ and Gossadi et $\mathrm{al}^{21}$ and is in agreement with the study done by Nasreen et $\mathrm{al}^{20}$ and Kashif et $\mathrm{al}^{24}$. The most frequent arch involved in this study is mandibular arch which contradicts the other study ${ }^{20}$. Jafarianet. $\mathrm{al}^{25}$ showed that the most persistent teeth extracted were lower third molars (18\%) followed by upper premolars $(14.77 \%)$ while lower canines $(3 \%)$ were the least frequently extracted which contradicts our study in which we found that the lower first molars $(12.50 \%)$ are the most frequently extracted teeth, followed by upper first molar $(9.64 \%)$ and lower second molar $(9.64 \%)$ and the least frequent teeth extracted are upper incisors(2.84\%). Regular dental checkups should be a routine pattern of behavior for all and preventive measurement needs to be implemented in order to decrease the level of caries amongst population. Diagnosing caries early before its progression may prevent the least wanted result of tooth extraction. It is also advocated that community awareness programs must be initiated and people must be emphasized for vigorous oral hygiene maintenance and strategies for screening periodontal disease might be required.

\section{CONCLUSION}

Caries is the dominant cause for teeth extractions followed by periodontal diseases and lower first molar is the prominent teeth involved in extraction.

\section{REFERENCES}

1. Ong G, Yeo JF, Bhole S. A survey of reasons for extraction of permanentteeth in Singapore. Community Dent Oral Epidemiol. Apr 1996;24(2):124-7.

2. Morenike OF, Olayinka DO, Temitope AE et al. Pattern of Dental Extraction in Children in a Nigerian Tertiary Hospital. J Contemp Dent Pract. May 2005 ;6(2):80-90.

3. Zadik Y, Sandler V, Bechor R, Salehrabi R. Analysis of factors related to extraction of endodontically treated teeth. Oral Surg Oral Med Oral Pathol Oral RadiolEndod. 2008 Nov;106(5):e31-5.

4. Adeyemo WL, Oderinu HO, Oluseye SB, Taiwo OA, Akinwande JA. Indications for extraction of permanent teeth in a Nigerian teaching hospital: a 16-year follow-up study. Nig Q J Hosp Med. 2008; 18(3):128-32.

5. Al-Shammari KF, Al-Ansari JM, Al-MelhMA, Al-Khabbaz AK. Reasons for tooth extraction in Kuwait. Med PrincPract 2006; 15:417-22.

6. Chen SC, Chueh LH, Hsiao CK, Wu HP, Chiang CP. First untoward events and reasons for tooth extraction after nonsurgical endodontic treatment in Taiwan. J Endod 2008;34: 671-674.

7. Chestnutt IG, Binnie VI, Taylor MM. Reasons for tooth extraction in Scotland. J Dent 2000; 28: 295297. 
8. Razak IA, Jaafer N, Matnor G. The causes of tooth mortality of permanent teeth in a Malaysian population. J Irish Dent Assoc 1989;35:39-41.

9. Mehta FS, Sanjara MK, Shroff BC. Analysis of periodontal disease as a cause of tooth loss. J Indian Dent Assoc 1960;32:71-6.

10. Haddad I, Haddadin K, Jebrin S, Ma'Ani M, Yassin O. Reasons for extraction of permanent teeth in Jordan. Int Dent J 1999; 49: 343-46.

11. Matthews DC, Smith CG, HanscomSL. Tooth loss in periodontal patients. J Can Dent Assoc 2001; 67: 207-10.

12. Angelillo IF, Nobile CG, Pavia M. Survey of reasons for extraction of permanent teeth in Italy. Community Dent Oral Epidemiol 1996; 24: 336-40.

13. Ong G, Yeo JF, Bhole S. A survey of reasons for extraction of permanent teeth in Singapore. Community Dent Oral Epidemiol 1996; 24: 124-7.

14. Al-Emran S. Prevelance of tooth lossin Saudi Arabia School children: An Epidemiological Study Of Saudi Male Children. S Dent J 1990; 2: 137-40.

15. Fure S, Zickert I. Incidence of tooth loss and dental caries in 60-, 70- and 80-year-old Swedish individuals. Community Dent Oral Epidemiol 1997; 25: 137-42.

16. Agerholm DM, Sidi $A D$. Reasons given for extraction of permanent teeth by general dental practitioners in England and Wales. Br Dent J 1988; 164: 345-8.

17. Klock KS, Haugejorden O. Primary reasons for extraction of permanent tooth inNorway: Changes from 1968-1988. Community Dent Oral Epidemiol 1991;19:336-41.

18. Corbet EF, Davies WI. Reasons given for tooth extraction in Hong Kong. Community Dent Health. 1991;8:121-30.

19. Naz F. Reasons for tooth extraction in permanent dentition: A study in a tertiary care setting in Pakistan. Oct-Dec 2011;20(4):235-38.

20. Nasreen Tand Haq M E.Factors of tooth extraction among adult patients attending in exodontia department of Dhaka Dental College and Hospital. Ban J Orthod and DentofacOrthop, Oct 2011;2 (1): 7-10.

21. Gossadi YI, Nahari HH, KinaniHM,AbdelwahabSI,Boreak NM, Abidi NH et al. Reasons For Permanent Teeth Extraction In Jizan Region Of Saudi Arabia. IOSR-JDMS. Jan-2015; 14(1)-VII:8689. DOI: 10.9790/0853-14178689.

22. McCaul LK, Jenkins WM, Kay EJ. Reasons for extraction of permanent teeth in Scotland-a 15 year follow up. J Dent 2001; 29: 401-07.

23. Haseeb M, Ali K, Munir MF. Causes of extraction in tertiary care hospital in Pakistan. J Pak Med Assoc august 2012 ;62 (8): 812-15.

24. Kashif M, Mehmood K, Ayub T, Aslam M. Reasons and Patterns of Tooth Extraction in a Tertiary Care Hospital- A Cross Sectional Prospective Survey. J LiaquatUni Med Health SciSEP-DEC 2014; 13(3):125-29.

25. Jafarian M, Etebarian A. Reasons for Extraction of Permanent Teeth in General Dental Practices in Tehran, Iran. Med PrincPract 2013;22:239-44.DOI: 10.1159/000345979. 